\title{
An investigation on the neighborhood of Iran's villages and cities (case study: Kondlous Chalous Village)
}

Investigación sobre el vecindario de los pueblos y ciudades de Irán (Estudio de caso: Kondlous Chalous Village)

Author:

Somayeh Noruzi,**

Shahrbanoo Samadai ${ }^{2}$

Mahdi Samadai ${ }^{3}$

\section{SCIENTIFIC RESEARCH}

How to cite this paper:

Noruzi. O., Samadai. S., Samadai. M. An investigation on the neighborhood of Iran's villages and cities (case study: Kondlous Chalous Village). Babol, Iran. Innovaciencia. 2019; 7 (2): 1-8. DOI:

http://dx.doi.org/10.15649/2346075X.768

Reception date:

Received: 21 January 2019

Accepted: 3 May 2019

Published: 25 October 2019

Keywords:

Residential complexes, Relations between inhabitants, Neighborhood units, Kandlous village

\section{ABSTRACT}

The design of residential complexes, taking into account neighborhoods in different parts of the building, can improve the quality of life of the users, human beings are created socially and physically and mentally requires communication and interaction of their own kind. In fact, communication is one of the most important and tangible elements of social life. In many residential complexes, due to the lack of desirable neighborhoods, the relationship between residents does not occur. In this case, many residents do not find this sense of satisfaction and belonging to the environment in which they live. In this research, the research method used is descriptive-analytic. Using library documents, surveying methods and direct observation of space, as well as field observations and questions from space users, to collect and analyze the data needed for research. Is. The results of the analysis of texture and neighborhoods of the Kandlos village as a case study show that the traditional neighborhood and Iranian neighborhoods are more flexible, more diverse, more complete and comprehensive, and using the principles of location Traditional Iranian can reproduce the concept of interaction and neighborhoods and used in the design of contemporary Iranian residential complexes.

Corresponding author: Somayeh Noruzi

Technical faculty of I Ghodsiyeh Sari, Email: somi_architect@yahoo.com

Islamic azad university, Babol branch, Babol, Iran

Islamic azad university, Babol branch, Babol, Iran 


\section{INTRODUCTION}

The house has always been considered by architects as the first habitation and space that human beings spend most of their time on, and from different perspectives it has been addressed. Attention to philosophical issues, sociology and psychology, cultural, aesthetics, performance, etc. are among these views.

Unhealthy homes, in addition to the body, affects psychosocial issues such as depression, depression, stress and behavioral abnormalities. In today's cities, people are looking for high-quality products to achieve their high perfection, in addition to providing comfort and engagement with their fellow citizens, in the context of social dynamism. One of the most important criteria of desirable quality in residential complexes is social capital (neighborhood), which can be achieved by focusing on this subject in a collective life.

According to Sumpson's definition, social capital is the connecting factor of two aspects of people in terms of trust and common interests and interests in order to intervene to accomplish common affairs within the community, which involves two aspects of social cohesion or the sense of association of members with He also has some kind of desire and interest in solving social problems.

Social interactions between individuals and maintaining belonging to the place as an effective relationship and linkage that people create with the place that in fact is the same meaningful atmosphere can be considered as the ideal result of designing an ideal special food in residential complexes. . The space formerly existing in the old neighborhoods, and the atmosphere of behavioral abundance, was a space that imposed social interactions on the individual. Neighborhoods have been determining the social relations of citizens.

In today's societies, solving the problems of population growth, modernization of life, poor construction, and the disproportionate prevalence of Western contemporary architecture has been raised by the desire of individuals to have private spaces toward the efficiency of public spaces in residential complexes. However, public spaces and communities of neighborhoods are in order to get rid of everyday tensions, leisure time, social interactions of the gathering of individuals and groups, and a place for presence, freedom of expression and expression in space. Public life depends on public spaces, promoting social interactions, attracting individuals and groups, social security and, consequently, increasing the tolerance of different groups in space, increasing socialization and creating a vibrant atmosphere.

The study seeks to identify neighborhoods and neighborhoods, neighborhoods and theirinteractions, and achieve architectural principles for the design of residential neighborhoods by identifying neighbors' concepts and definitions.

\section{NEIGHBOR AND NEIGHBORHOOD}

Dehkhoda's dictionary reads: Neighborhood means neighboring, adjacent, adjacent, and neighboring means wall, two or two families living side by side or two parts of a house.

Neighboring or adjacent synonyms are those in which they are eligible for close proximity, bondage, calling, affiliation, affiliation, and the relationship between two or more objects. Sociologists have a general interpretation of neighborhoods. And the idea that the neighborhood is the perfect example of the first group and advocates it as a neighborhood, in coexistence of members or social groups, that this neighborhood in coexistence leads to understanding of relationships and social relationships in different dimensions.

In the old neighborhoods of Iran, if two houses were located nearby, but in two different stages, and did not know each other as neighbors, neighbor and neighborhood were only possible in a single neighborhood. 


\section{NEIGHBORHOOD UNIT}

Although neighboring quality has long existed for bio-complexes, the term neighborhoods, which has been a scientific key word since the early 1910s, is a model for planning a basic chart for residential development in urban areas.

This concept acts as a framework for urban planners who, at the beginning of the twentieth century, are working in urban industrial towns to design functional, autonomous and desirable areas. It continues to be used as a means of combining and organizing new residential communities in line with social, administrative, and modern social services and for satisfactory urban conditions.

Below are the most important definitions of the neighborhood unit that covers the various dimensions and meanings:

Neighborhood is a word and a subjective and abstract concept. For some, this word is limited only to a number of blocks and a number of residential units or neighboring buildings.

Neighborhood units are the places where people live, in other words, the neighboring units signify a sense of belonging to a place where the memories and lives of the people are recorded.

Neighborhood unit of a local area or local area of some places is defined as a distinguishable position from a metropolitan area, an area consisting of various and different uses that are integrated within the structure of an integrated city. The urban area has a wide range of types of buildings, passages and public spaces that offer a variety of human activities.

Neighborhood unit is one of the main constituent units of the city. Moderate physical units that increase the living space of each city and shape the environment in which people live every day.

From the perspective of the American Planning Association, the Neighborhood is a diverse entity and socio-economic dynamism with unique features that are recognized by neighboring and community members and solutions. A neighboring neighborhood of a planned urban area, combined with It is a human activity organized around a defined center.

Neighborhood is an ecosystem that is the only shelter for the human habitation and human being needed, but also a network of social support and opportunities for a wide range of leisure, cultural and economic activities, with which the natural habitat neighborhood is defined, with which other human beings in a relationship Living Symbiosis Applied Systems (Artificial Natural) control the flow of energy and water and affect the quality of air and soil.

Neighborhood unit is an interconnected set of houses (families), among which neighborhoods (neighborhood relationships) are concentrated in a special space called the Neighborhood Center in a set of well-defined spaces, while the similarities and aspects of the subscription Physical, economic and belief can also help define other forms of neighborhoods or to complete this general definition.

Definition of neighborhoods In other words, residential units (houses) also have a place where normal and abnormal behavior of their inhabitants directly affects each other.

To share physical features (location) is the following:

- Joint infrastructure

- Roofs relationshipzz

- Being close (in terms of access to vehicles and everyday services from shared locations)

- Have aristocracy (or relative to one another or one aspect)

- Inputs are relatively close and visible

- Access permissions in the ranking

- Have an adjacency

The name of the Neighborhood Unit is the term to design possible arrangements in residential 
complexes. Research shows that residential complexes, with family life needs, share similar areas and perform similar functions.

In a neighboring system, these elements form a whole natural unit alongside each other.

This paper seeks to introduce some of the basic, spatial, and social principles that exist in neighborhoods and old neighborhoods and neighborhoods by examining the village of Kandlvs as one of the rich neighborhoods in Iran.

Theprinciples are: the principle of spatialorganization, the principle of scale and proportionality, the principle of hierarchy, the principle of diversity and diversity of space, the principle of continuity of space, the principle of culture and climate

\section{CASE STUDY: KANDLOUS VILLAGE}

The village of Kandluz is located in Kojur district, $75 \mathrm{~km}$ south-east of Noshahr. The Kandlos village is located in a mountainous area in one of the beautiful valleys of the Alborz mountains and is 1650 meters above sea level.

According to archaeologists, the historic history of the Kennelus Village dates back to the third millennium

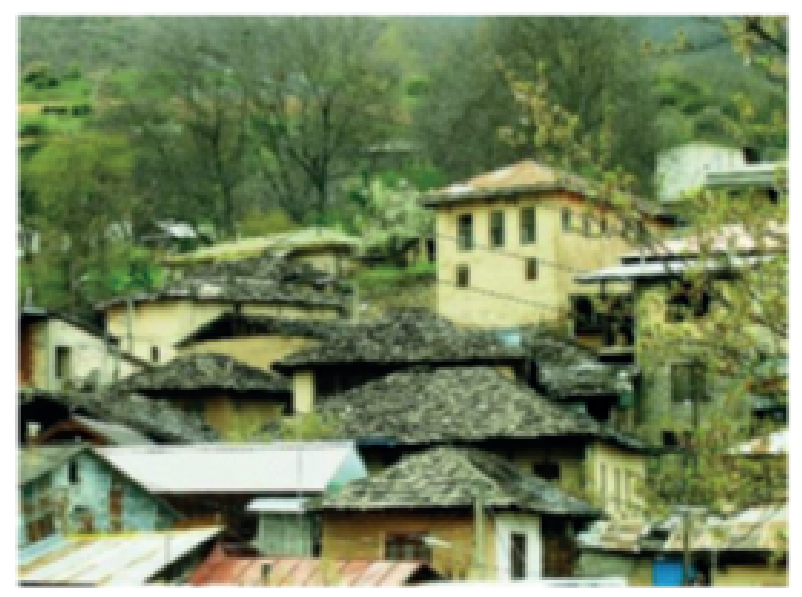

BC. The village witnessed various civilizations in different historical periods, and the signs of preBCE civilization, Iran's pre-Islamic civilization, have been the source of Iranian civilization after Islam.

Examining the architectural structure of an architect (people's architect) of this village and its neighboring units can be reached.

\subsection{The principle of spatial organization}

The organization of the space that is based on the link between the village center and neighboring units is based on the main, secondary and field tracks.

In the village of Kandluss, where the texture is densely populated, it can be seen on the gentle slopes of the mountain slope. The main passage of the center of the neighborhood originates from the center of the neighborhood and proceeds according to the topographic conditions of the earth. This passes every time openings or photos Contractions in their structure. To the point where its internal energy is reduced, and in such places, organically, the circle is formed in the general structure. Also, wherever the duplication requirement occurs, the alleys begin to grow naturally from within it. Each of these alleys, in its developmental cycle, undergoes openings and contractions in accordance with the natural conditions of the earth. And are linked in a variety of ways, in most cases no stalactites are experienced in this context.

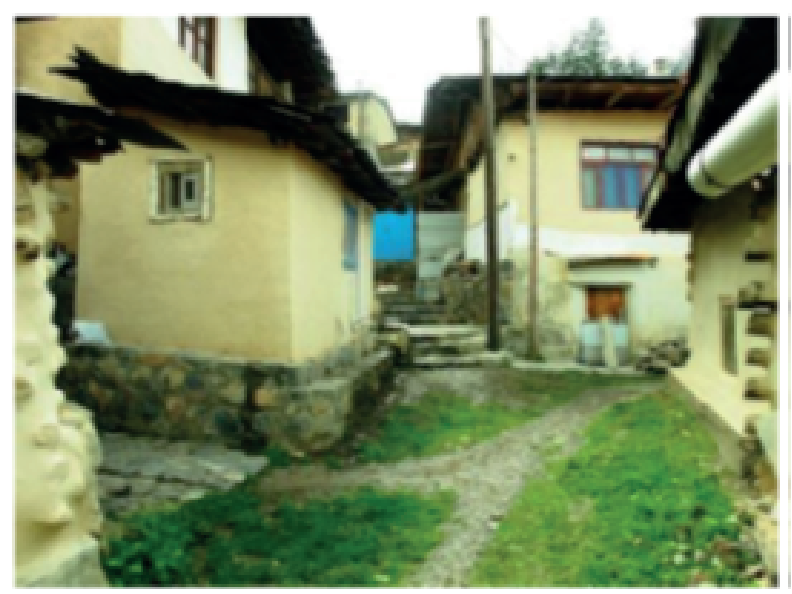

Figure 1: The main passive position and the dense clamor of the village on the slope 


\subsection{Principle of Scale and Fit}

In the structure of the neighboring village of Kandlous, the width and height of the spaces are according to these human proportions. The spaces

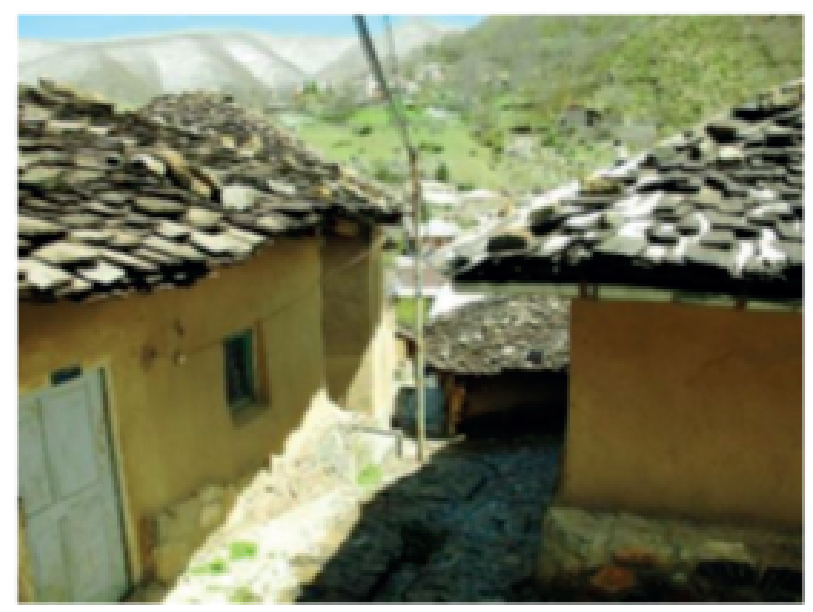

needed daily for residents are located within a short distance of them with easy access for the pedestrians. The outer walls of the buildings are simple and the entire residential complexes are textured from the outside and are free from any vignette.

Figure 2: The human proportions of the village passage and easy access for hikes

\subsection{The principle of hierarchy}

The hierarchy plays an important role in defining components in the form of a set and identifying them. Otherwise, it can be said that preserving and applying values such as confidentiality, calmness, security, privacy, and attention to the inside and outside can easily be created through the hierarchy.

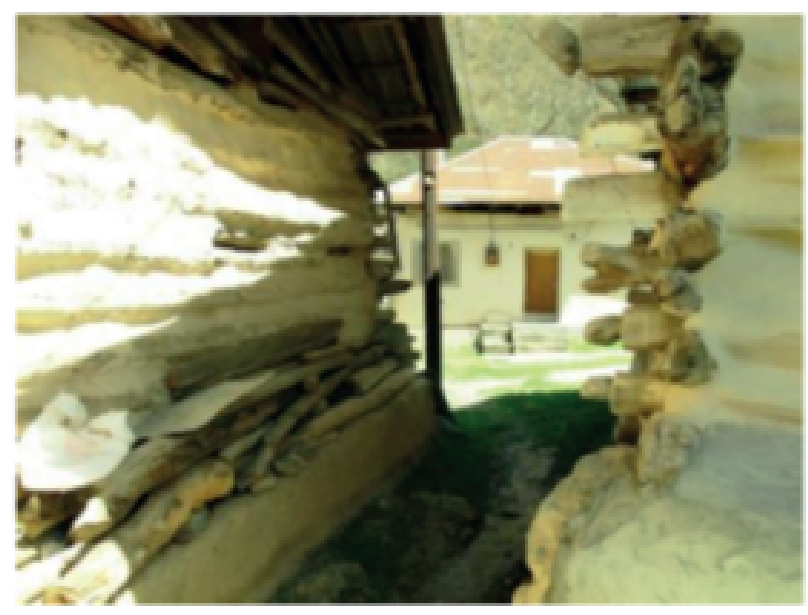

In the village of Kendlous, this principle is also seen in three ways:

- A local hierarchy of access that includes main and secondary routes that reach neighboring neighborhoods.

- Functional hierarchy, which includes the establishment of public services and functions in the center of the neighborhood and subsequently neighboring units.

- A public-private hierarchy that responds to the privacy and scope of neighborhood neighborhoods.
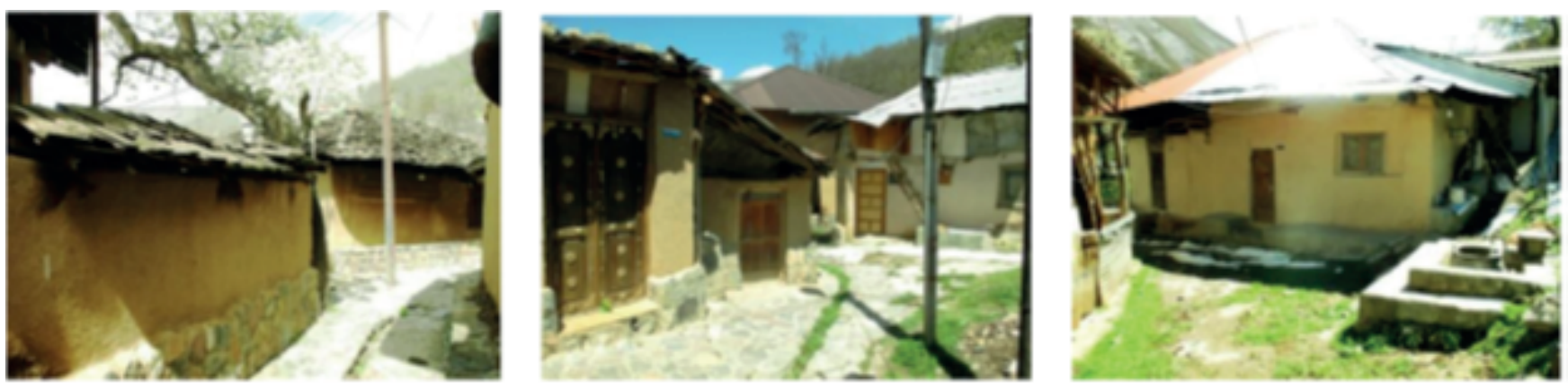

Figure 3: Hierarchy of Functional Access and Public Private Space 


\subsection{The principle of diversity and spatial diversity}

The main causes of dystonia in the context of the Kandlos village context can be identified.

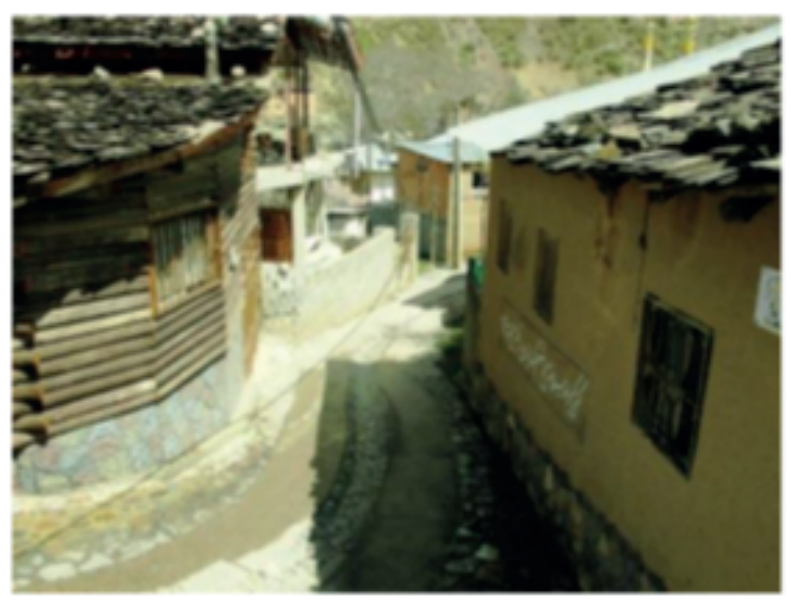

The directness of passages from the beginning to the end, the spatial openings in the main passages, the narrow and narrowing of the paths and the spaces with the topography of the earth, the existence of spatial openings in neighboring units are examples of it.

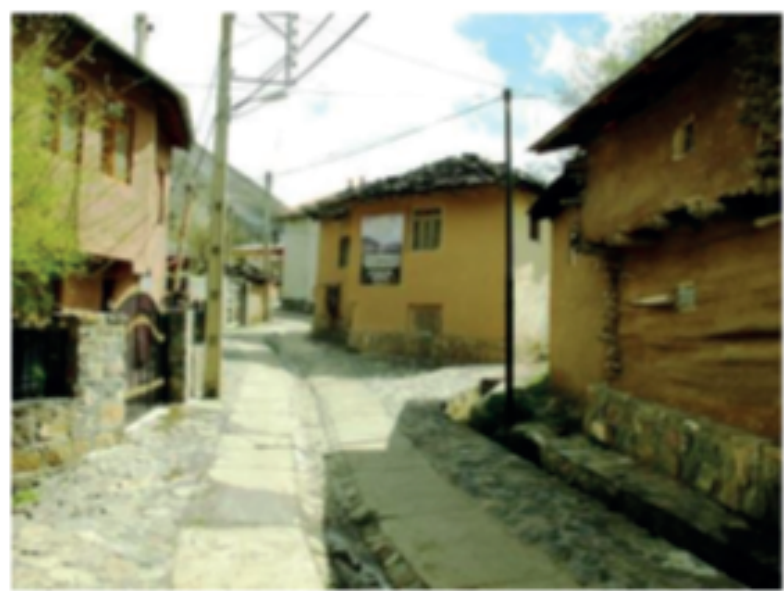

Figure 4: I'm narrowing down to change the direction of the paths as well as the opening up of the spaces of the brain

\subsection{The principle of unity and spatial continuity}

The texture of the village of Kandlos has a special cohesion and diversity along with the diversity of spaces. In this village, the residential spaces

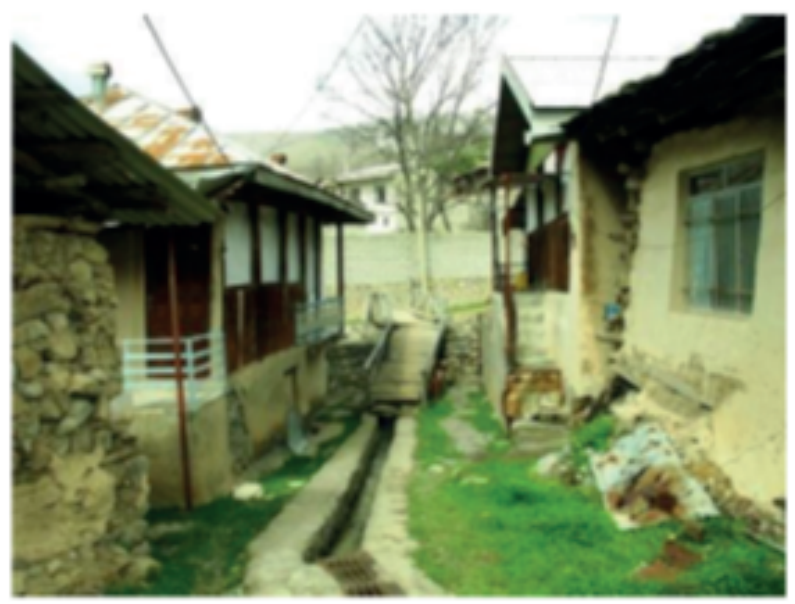

Figure 5: Consistency unity of reservoir spaces (neighboring units) and non-residential areas like the baths, mosques, emamzadeh and commercial spaces are so connected and interconnected that they have come in a continuous form.

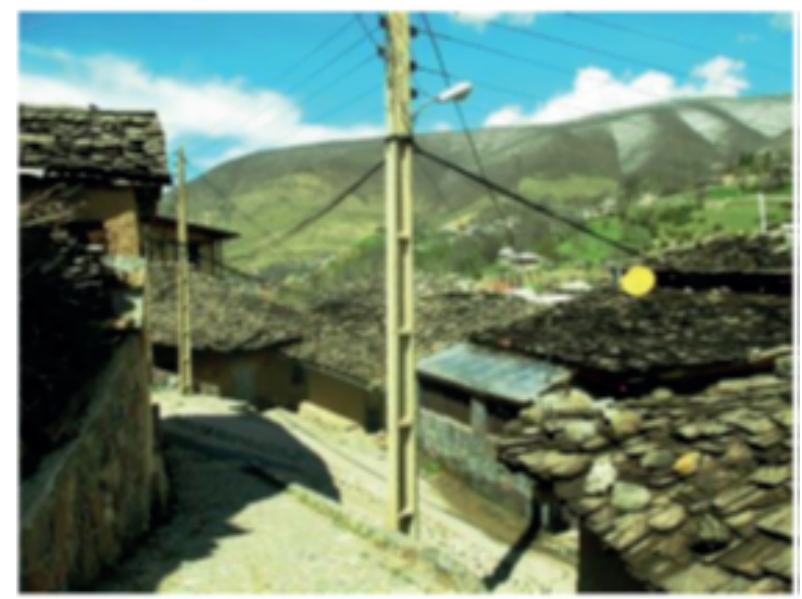




\subsection{Principle of culture and climate}

There have always been various factors such as culture and climate that have created a link, social unity and solidarity in neighborhoods and neighborhoods.

The influence of culture on the formation of spatial structures based on indigenous and popular structures, in the area of perception of elements and elements of space, as well as its relationship with nature.

In the village of Kandlvs, you can see the impact of culture and climate in neighborhoods, as well as on the alley and its outskirts.

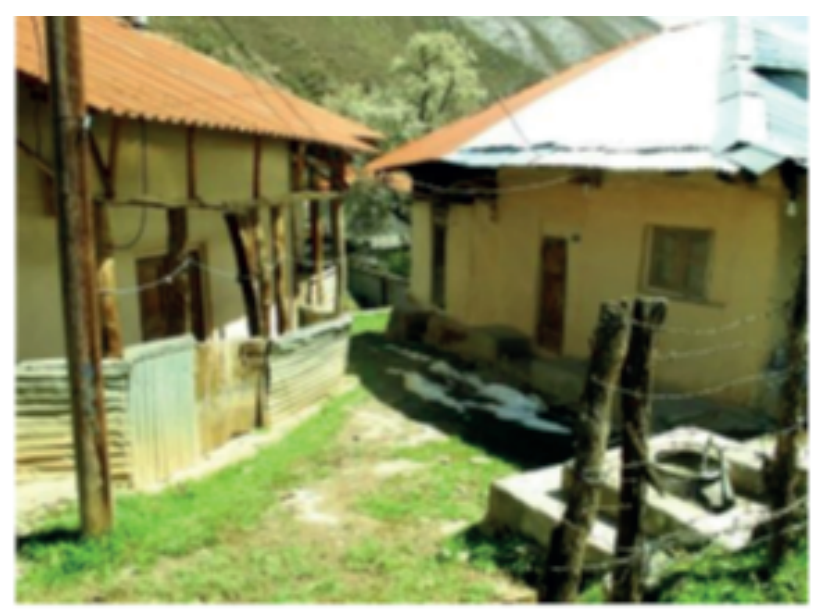

Slender houses with natural materials are indigenous and they are made from inside and outside with wood.

The exterior of the glitches that are placed together are covered. This roof, in addition to giving a beautiful natural day and readability, is a rain-storm that takes away the wood from the forest and the rain and rain. On this basis, what can be seen in the architecture of the Kilduys Residential Complex. , The presence of native culture and climate along with a harmony in the utilization and revitalization of the traditional and indigenous structure of the region has become effective.

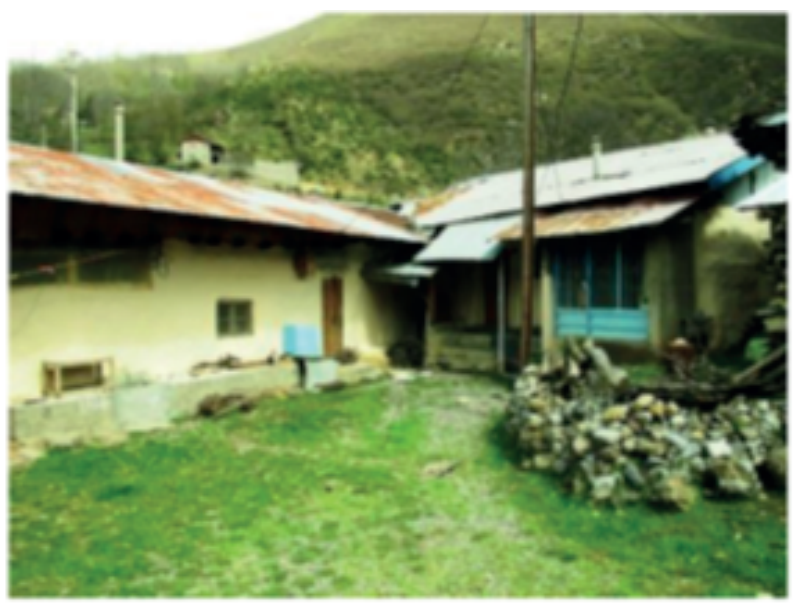

Figure 6: The Impact of Culture and Climate on the Formation of Shrines

\section{CONCLUSION}

In this study, the village of Kandlous was selected to gain a better understanding of the concept of neighborhoods.

By studying the structure inside the village, the location of neighboring units also became clearer.

With the advent of a path, it can be seen that in various ways peoples are exposed in different situations. The benefit of the residents and their level of intelligence in using these openings in favor of a daily life and in accordance with culture and traditions in the form of neighborhood units is something that has been seen repeatedly in this village. Each of these spatial discoveries continues to evolve in the form of alleyways and, in the future, a new opportunity for another opening, which turns into a new neighborhoods. In other words, it reveals its structure that interconnects in a food package of alleys and neighborhoods in different ways.

This continuity and lack of space stalemate are the main features of the structure, which can be used as a template for the formation of new residential complexes. 


\section{REFERENCES}

1. Qanbaran, A., Jafari, M., Investigando los factores que afectan la promoción de las interacciones sociales entre los residentes del vecindario residencial (Estudio de caso: Darehahr, Teherán) Journal of Urban Management 2014.

2. Coughhy MO, O'Campo PJ., Neighborhood Poverti, Social Capital, y African Amirican Preschoolers, Amiricans Journal of Community Psychology, vol 37,141-151,2006.

3. Khaksari, A, Barrios urbanos en Irán, Instituto de Investigación de Humanidades y Estudios Culturales. 1391.

4. Zarghami, A, Sostenibilidad social en complejos residenciales, Doctorado en Arquitectura, Universidad de Ciencia y Tecnología, Facultad de Arquitectura y Desarrollo Urbano, Teherán, 2008

5. Sennette, R. La caída del hombre público. Nueva York: W W Norton \& Company, 1974.

6. Whyte, W, H. La vida social del pequeño espacio urbano. Smoking, Maryland: Printers II Inc. 1980.

7. Marcus, C.C. , Francis C. People Places: Líneas de guía de diseño para espacios abiertos urbanos. Nueva York: NY: Van Nostrand Reinhold. 1998

8. Mirza Mohammadi, D, Pautas para mejorar las necesidades de la unidad de vecindario de Yazd, Universidad de Yazd, 1396
9. Banerjee, T. Baer, W. 'Capítulo 1: Introducción' en la Unidad Más allá del vecindario: Entornos residenciales y políticas públicas, Plenum Press, Nueva York, pág. 1-11, 1984.

10. Perry, C. The Neighborhood Unit (1929) Reimpreso Routledge / Thoemmes, Londres, p.25-44, 1998.

11. Abbaszadeh, Sh, Rouhani, A. (Comparación de los vecindarios residenciales en Irán y los vecindarios en el Oeste en términos del concepto de interacciones sociales (Cuarta Conferencia Internacional sobre Tecnologías Modernas en Ingeniería Civil, Arquitectura y Desarrollo Urbano, Teherán.

12. Mirza Mohammadi, D, Pautas para mejorar la utilidad en la tesis de maestría de la Unidad de Vecindarios

13. Perry, Clarence Arthur, Unidad de Vecindarios Traducción Kianoush Zaker Haghighi, Shams No.335, 1929.

14.http://zarintravel.ir

15. Tavassoli, M., Diseño urbano en la textura antigua de la ciudad de Yazd, 1367.

16. Latifi, Gh, Safari, Aghak, N, revisado El concepto de vecindario en ciudades iraníes-islámicas basadas en el nowsherazismo. 